\title{
Visceral Obesity Is Associated with Gallbladder Polyps
}

Jun Kyu Lee*, Suk Jae Hahn*, Hyoun Woo Kang*, Jae Gu Jung*, Han Seok Choi*, Jin Ho Lee*, In Woong Han ${ }^{\dagger}$, Jin-Hee Jung $^{\ddagger}$, and Jae Hyun Kwon ${ }^{\ddagger}$

Departments of *Internal Medicine, ${ }^{\dagger}$ Surgery, and ${ }^{\ddagger}$ Radiology, Dongguk University Ilsan Hospital, Dongguk University College of Medicine, Goyang, Korea

Background/Aims: Gallbladder polyps (GBP) are a common clinical finding and may possess malignant potential. We conducted this study to determine whether visceral obesity is a risk factor for GBP. Methods: We retrospectively reviewed records of subjects who received both ultrasonography and computed tomography with measurements of the areas of visceral adipose tissue and total adipose tissue (TAT) on the same day as health checkups. Results: Ninety-three of 1,615 subjects (5.8\%) had GBP and were compared with 186 ageand sex-matched controls. VAT (odds ratio [OR], 2.941; 95\% confidence interval $[\mathrm{Cl}], 1.325$ to $6.529 ; \mathrm{p}=0.008$ for the highest quartile vs the lowest quartile) and TAT (OR, 3.568; $95 \% \mathrm{Cl}, 1.625$ to $7.833 ; p=0.002$ for the highest quartile vs the lowest quartile) were independent risk factors together with hypertension (OR, 2.512; $95 \% \mathrm{Cl}, 1.381$ to 4.569; $\mathrm{p}=0.003)$, diabetes mellitus (OR, 2.942; $95 \% \mathrm{Cl}, 1.061$ to 8.158; $p=0.038)$, hepatitis $B$ virus positivity $(O R, 3.548$; $95 \% \mathrm{Cl}, 1.295$ to $9.716 ; p=0.014)$, and a higher level of total cholesterol (OR, 2.232; $95 \% \mathrm{Cl}, 1.043$ to $4.778 ; \mathrm{p}=0.039$ for $<200 \mathrm{mg} / \mathrm{dL}$ vs $\geq 240 \mathrm{mg} / \mathrm{dL}$ ). Body mass index and waist circumference were not meaningful variables. Conclusions: Visceral obesity measured by VAT and TAT was associated with GBP irrespective of body mass index or waist circumference. (Gut Liver 2016;10:133-139)

Key Words: Gallbladder polyp; Obesity, abdominal; Adipose tissue; Metabolic syndrome; Risk factors

\section{INTRODUCTION}

Gallbladder polyps (GBP) are defined as any mucosal projections protruding into the lumen of gallbladder (GB). The prevalence rate of GBP assessed by abdominal ultrasonography (USG) is $3 \%$ to $12 \%$ of the general population. ${ }^{1-4}$ The incidental detection of GBP has been increasing due to recent advances in imaging technology and the widespread use of USG for routine health checkups. Pathologically, cholesterol polyp is the most common and accounts for 46\% to 70\% of all GBP. ${ }^{1,5,6}$ Hyperplasia, leiomyoma and inflammatory polyps and adenoma also occur. Possibility of malignancy is elevated markedly when the size is $>10 \mathrm{~mm}$, for which case cholecystectomy is recommended. ${ }^{5}$

The risk factors for GBP are not established clearly despite its clinical importance. Although old age, male gender, and metabolic syndrome are possibly associated with GBP, results were not always consistent. ${ }^{7-10}$ Especially, there were conflicting reports for obesity. ${ }^{11-13}$ In this study, we evaluated obesity measured in terms of visceral fat using computed tomography (CT) as a risk factor for GBP.

\section{MATERIALS AND METHODS}

\section{Study populations}

A retrospective, cross-sectional study was conducted on subjects who visited Medical Screening Center, Dongguk University Ilsan Hospital for health checkups between January 2006 and December 2011. GBP were evaluated with USG and visceral obesity was measured with $\mathrm{CT}$; hence, subjects who received both examinations on the same day were selected. A control group matched for age and sex, both of which were considered as important confounders in previous studies, ${ }^{3}$ was formed with the ratio of 1:2. Following baseline demographic variables and the results of biochemical tests were collected as possible risk factors: body mass index (BMI), waist circumference, hyperten-

Correspondence to: Hyoun Woo Kang

Department of Internal Medicine, Dongguk University Ilsan Hospital, Dongguk University College of Medicine, 27 Dongguk-ro, Ilsandong-gu, Goyang 10326, Korea

Tel: +82-31-961-7750, Fax: +82-31-961-9309, E-mail: gangmali@naver.com

Received on December 19, 2014. Revised on March 19, 2015. Accepted on March 22, 2015. Published online August 11, 2015

pISSN 1976-2283 eISSN 2005-1212 http://dx.doi.org/10.5009/gnl14506

Jun Kyu Lee and Suk Jae Hahn contributed equally to this article as the co-first authors.

(.) This is an Open Access article distributed under the terms of the Creative Commons Attribution Non-Commercial License (http://creativecommons.org/licenses/by-nc/4.0) which permits unrestricted non-commercial use, distribution, and reproduction in any medium, provided the original work is properly cited. 
sion, diabetes mellitus (DM), hepatitis B surface antigen (HBsAg), hepatitis $\mathrm{C}$ virus antibody (HCV Ab), total cholesterol, triglyceride (TG), high-density lipoprotein (HDL) cholesterol, highsensitivity C-reactive protein (hs-CRP), aspartate aminotransferase (AST), alanine aminotransferase (ALT), alkaline phosphatase, and tumor markers (CEA and CA 19-9). This study was conducted in accord with the Helsinki Declaration and approved by the Institutional Review Board of Dongguk University Ilsan Hospital (DUIHIRB 2012-104).

\section{Evaluation of GBP}

After 10 hours of fasting, ultrasonographic examinations was performed using the iU22 ultrasound system (Philips Healthcare, Bothell, WA, USA) with C5-1 abdominal probe. Immobile, nonshadowing mucosal projection attached to the wall and protruding into the lumen of GB were diagnosed as GBP. The size and number of GBP were described according to a unified report form.

\section{Measurement of visceral obesity}

To measure visceral obesity, a 64-slice multidetector CT scanner (Somatom Sensation 64; Siemens Medical Solutions, Forchheim, Germany) was used and the area of adipose tissue was calculated with high degree of validity and reproducibility, as previously described. ${ }^{14,15}$ At the level of umbilicus, the area of total adipose tissue (TAT) was discriminated by setting the attenuation values specific for fat ( -250 to -50 Hounsfield units) and calculated automatically with commercially available software (Syngo CT 2011A; Siemens Medical Solutions, Forchheim, Germany).

Visceral adipose tissue (VAT) was defined as an area of intraabdominal adipose tissue bounded by parietal peritoneum excluding paraspinal muscles and the vertebral column (Fig. 1). The boundaries of total and visceral adipose tissue were distinguished using a manual tracing method, as previously described. ${ }^{16}$ Because a normal range of the amount of abdominal adipose tissue has not been defined as an absolute cutoff value, the lowest quartiles of VAT and TAT were used as references in this study.

\section{Statistical analysis}

The differences of categorical variables were analyzed using the chi-square test. Continuous variables, the mean of which were expressed as means \pm standard deviation, were compared using the Student t-test. The relationships between the size of GBP and TAT or VAT were evaluated using the Pearson correlation analysis. The results of univariate analysis were expressed by the odds ratio (OR) and 95\% confidence interval (95\% CI).

Age in decades and variables with $p$-values $<0.05$ by univariate analysis were put into forward stepwise multiple logistic regression models to predict the best risk factors. They were categorized according to reference values or the ATP III-WPRO and ATP-III NCEP as follows: ${ }^{17,18}$ age $(<30,30-39,40-49,50-59$, $60-69$, and $\geq 70$ years), BMI ( $<18.5 \mathrm{~kg} / \mathrm{m}^{2}$ as underweight, $\geq 18.5$ $\mathrm{kg} / \mathrm{m}^{2}$ but $<23 \mathrm{~kg} / \mathrm{m}^{2}$ as normal weight, $\geq 23 \mathrm{~kg} / \mathrm{m}^{2}$ but $<25 \mathrm{~kg} / \mathrm{m}^{2}$ as overweight, $\geq 25 \mathrm{~kg} / \mathrm{m}^{2}$ but $<30 \mathrm{~kg} / \mathrm{m}^{2}$ as moderate obesity

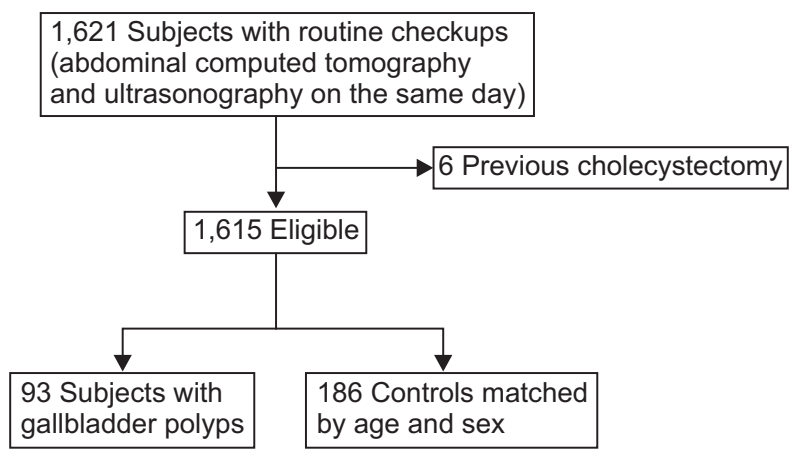

Fig. 2. Flow chart showing selection of the study population.
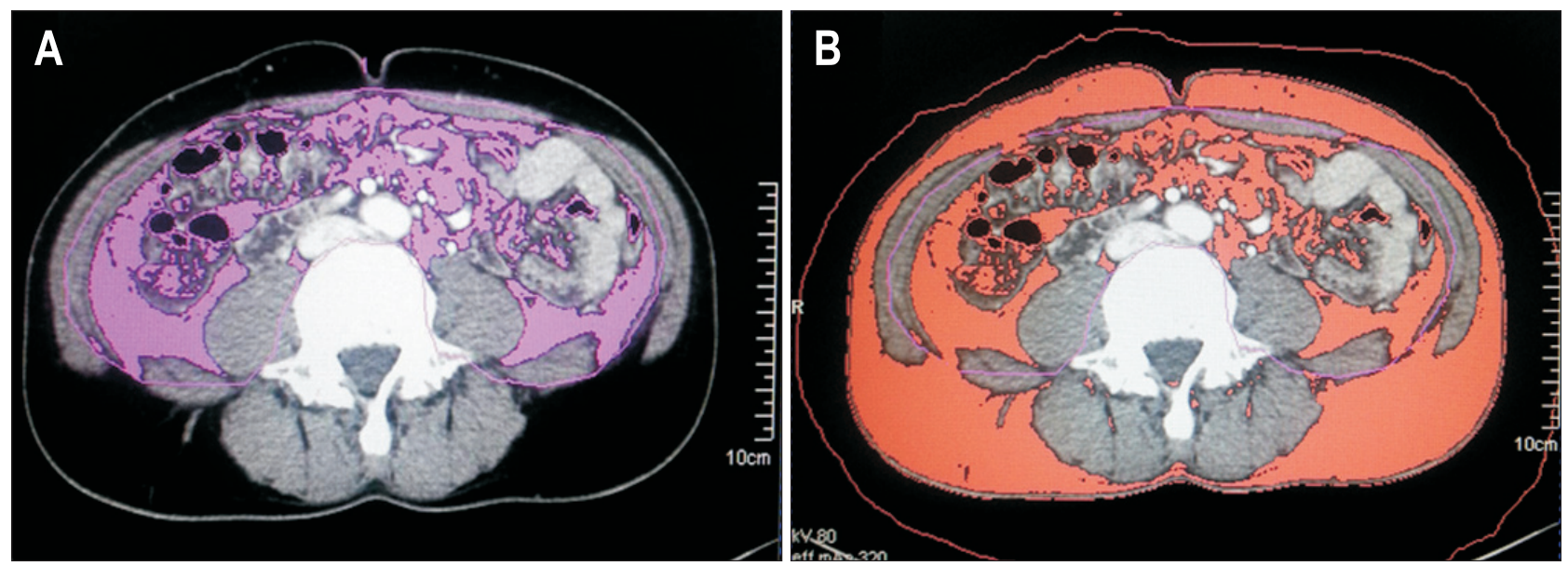

Fig. 1. Measurement of visceral obesity. The areas of visceral adipose tissue (A) and total adipose tissue (B) were measured using computed tomography at the umbilicus level. 
Table 1. Age Distribution of the Whole Study Population and Subjects with Gallbladder Polyps

\begin{tabular}{|c|c|c|c|c|c|c|}
\hline \multirow{2}{*}{ Age, yr } & \multicolumn{3}{|c|}{$\begin{array}{l}\text { Whole study population } \\
\qquad(\mathrm{n}=1,615)\end{array}$} & \multicolumn{3}{|c|}{$\begin{array}{l}\text { Subjects with gallbladder polyps } \\
\qquad(\mathrm{n}=93)\end{array}$} \\
\hline & Male & Female & Total & Male, no. (\%) & Female, no. (\%) & Total, no. (\%) \\
\hline$<30$ & 16 & 17 & 33 & $2(12.5)$ & 0 & $2(6.1)$ \\
\hline $30-39$ & 217 & 139 & 356 & $11(5.1)$ & $7(5.0)$ & $18(5.1)$ \\
\hline $40-49$ & 368 & 178 & 546 & $18(4.9)$ & $14(7.9)$ & $32(5.9)$ \\
\hline $50-59$ & 243 & 183 & 426 & $15(6.2)$ & $7(3.8)$ & $22(5.2)$ \\
\hline $60-69$ & 100 & 108 & 208 & $9(9.0)$ & $9(8.3)$ & $18(8.7)$ \\
\hline$\geq 70$ & 21 & 25 & 46 & 0 & $1(4.0)$ & $1(2.2)$ \\
\hline Total & 965 & 650 & 1,615 & $55(5.7)$ & $38(5.9)$ & $93(5.8)$ \\
\hline
\end{tabular}

Table 2. Characteristics of Gallbladder Polyps (n=93)

\begin{tabular}{lc}
\hline Characteristic & Value \\
\hline Size, mm & $4.8 \pm 2.7$ \\
Size classification, mm & $59(63.4)$ \\
$<5$ & $29(46.0)$ \\
$5-10$ & $5(5.4)$ \\
$\geq 10$ & $1.7 \pm 1.4$ \\
Mean no. & \\
Multiplicity & $63(67.7)$ \\
Single & $30(32.3)$ \\
Multiple & $5(5.4)$ \\
Cholecystectomy & $4(80.0)$ \\
Cholesterol polyp & $1(20.0)$ \\
Adenomyomatosis &
\end{tabular}

Data are presented as mean \pm SD or number $(\%)$.

Table 3. Comparisons of the Areas of Total and Visceral Adipose Tissue between Single versus Multiple Gallbladder Polyps ( $\mathrm{n}=93$ )

\begin{tabular}{lrrr}
\hline & $\begin{array}{c}\text { Single } \\
(\mathrm{n}=30)\end{array}$ & $\begin{array}{c}\text { Multiple } \\
(\mathrm{n}=63)\end{array}$ & p-value \\
\hline Total adipose tissue, $\mathrm{cm}^{2}$ & $139.23 \pm 43.26$ & $141.27 \pm 45.82$ & 0.839 \\
Visceral adipose tissue, $\mathrm{cm}^{2}$ & $57.88 \pm 25.59$ & $55.35 \pm 21.86$ & 0.624 \\
\hline
\end{tabular}

Data are presented as mean \pm SD.

and $\geq 30 \mathrm{~kg} / \mathrm{m}^{2}$ as severe obesity), waist circumference ( $>90 \mathrm{~cm}$ vs $\leq 90 \mathrm{~cm}$ for male and $>80 \mathrm{~cm}$ vs $\leq 80 \mathrm{~cm}$ for female), hypertension (systolic blood pressure $\geq 130 \mathrm{~mm} \mathrm{Hg}$ or diastolic blood pressure $\geq 85 \mathrm{~mm} \mathrm{Hg}$ or previously diagnosed hypertension versus null), DM (a fasting glucose of $\geq 126 \mathrm{mg} / \mathrm{dL}$ or previously diagnosed DM vs null), total cholesterol $(<200,200-240$, and $\geq 240 \mathrm{mg} / \mathrm{dL}$ ), TG ( $<150$ and $\geq 150 \mathrm{mg} / \mathrm{dL})$ and HDL cholesterol ( $>40 \mathrm{mg} / \mathrm{dL}$ vs $\leq 40 \mathrm{mg} / \mathrm{dL}$ for male and $>50 \mathrm{mg} / \mathrm{dL}$ vs $\leq 50 \mathrm{mg}$ / $\mathrm{dL}$ for female). OR and $95 \% \mathrm{CI}$ were computed using conditional logistic regression. Data were analyzed using R-software (http://www.R-project.org).

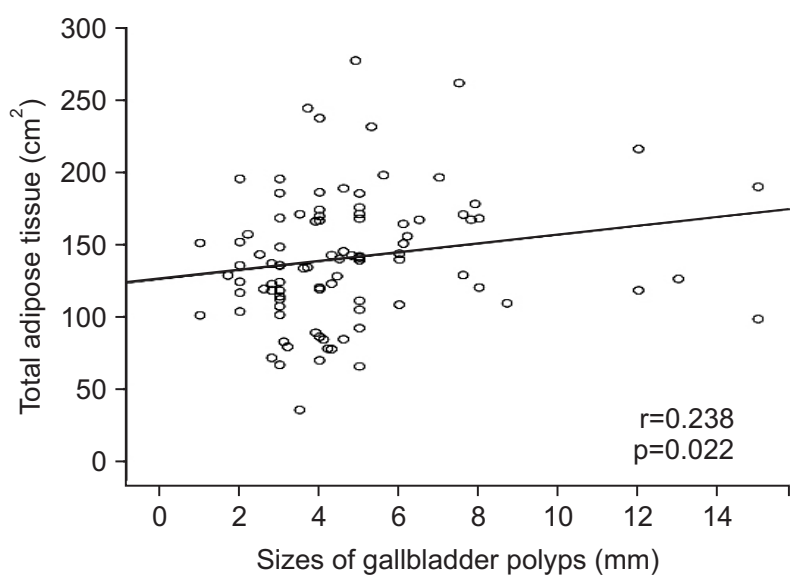

Fig. 3. A scatter plot showing the relationship between the sizes of gallbladder polyps and total adipose tissue.

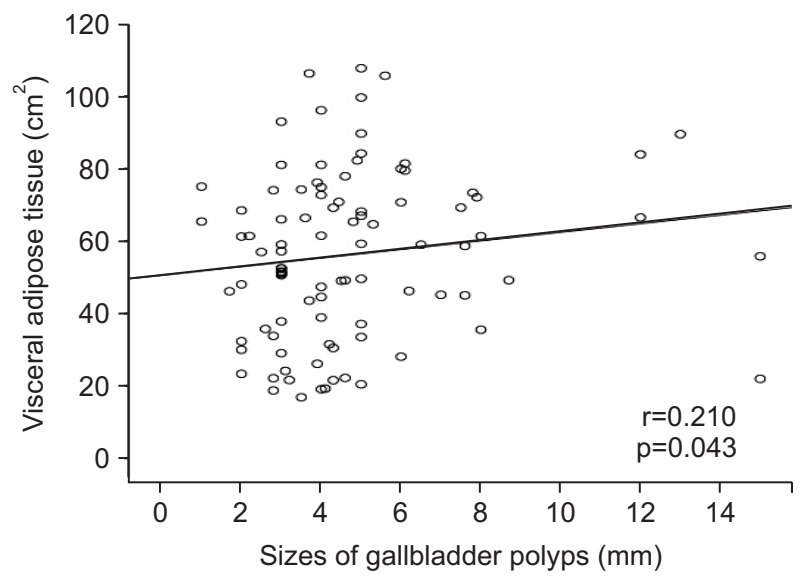

Fig. 4. A scatter plot showing the relationship between the sizes of gallbladder polyps and visceral adipose tissue.

\section{RESULTS}

\section{Prevalence and characteristics of GBP in healthy subjects}

There were a total 1,621 subjects who received USG and CT on the same day. As six were excluded due to previous cholecystectomy, the final analysis was performed on 1,615 subjects. Ninety-three subjects (5.8\%) had GBP and were compared with 
Table 4. Univariate Analysis of Possible Risk Factors for Gallbladder Polyps

\begin{tabular}{|c|c|c|c|c|}
\hline \multirow{2}{*}{ Variable } & \multicolumn{2}{|c|}{ Gallbladder polyp } & \multirow{2}{*}{ OR $(95 \% \mathrm{Cl})$} & \multirow{2}{*}{$\mathrm{p}$-value } \\
\hline & Yes $(n=93)$ & No $(n=186)$ & & \\
\hline \multicolumn{5}{|l|}{ Age group by decade, yr } \\
\hline$<30$ & 2 & 4 & 1.000 & \\
\hline $30-39$ & 18 & 34 & $1.059(0.177-6.348)$ & 0.950 \\
\hline $40-49$ & 32 & 68 & $0.941(0.164-5.409)$ & 0.946 \\
\hline $50-59$ & 22 & 42 & $1.048(0.198-6.175)$ & 0.959 \\
\hline $60-69$ & 18 & 36 & $1.000(0.167-5.985)$ & 0.999 \\
\hline$\geq 70$ & 1 & 2 & $1.000(0.053-18.915)$ & 0.999 \\
\hline \multicolumn{5}{|l|}{ BMI, $\mathrm{kg} / \mathrm{m}^{2}$} \\
\hline$<18.5$ & 2 & 5 & 1.000 & \\
\hline$\geq 18.5,<23$ & 31 & 118 & $0.657(0.122-3.548)$ & 0.625 \\
\hline$\geq 23,<25$ & 25 & 41 & $1.524(0.275-8.459)$ & 0.630 \\
\hline$\geq 25,<30$ & 31 & 21 & $3.690(0.654-20.835)$ & 0.139 \\
\hline$\geq 30$ & 4 & 1 & $10.000(0.648-154.397)$ & 0.099 \\
\hline \multicolumn{5}{|l|}{ Waist circumference, cm } \\
\hline$\leq 90(\mathrm{M}), \leq 80(\mathrm{~F})$ & 53 & 123 & 1.000 & \\
\hline$>90(\mathrm{M}),>80(\mathrm{~F})$ & 40 & 63 & $1.473(0.884-2.455)$ & 0.137 \\
\hline \multicolumn{5}{|l|}{ Hypertension } \\
\hline No & 65 (69.9) & $155(83.3)$ & 1.000 & \\
\hline Yes & $28(30.1)$ & 31 (16.7) & $2.196(1.323-3.644)$ & 0.002 \\
\hline \multicolumn{5}{|l|}{ Diabetes mellitus } \\
\hline No & $71(87.1)$ & $176(94.6)$ & 1.000 & \\
\hline Yes & $12(12.9)$ & $10(5.4)$ & 2.607 (1.082-6.283) & 0.033 \\
\hline \multicolumn{5}{|l|}{ HBsAg } \\
\hline Negative & $71(87.1)$ & $178(95.7)$ & 1.000 & \\
\hline Positive & $12(12.9)$ & $8(4.3)$ & 3.296 (1.297-8.374) & 0.012 \\
\hline \multicolumn{5}{|l|}{ Anti-HCV Ab } \\
\hline Negative & $91(97.8)$ & $185(99.5)$ & 1.000 & \\
\hline Positive & $2(2.2)$ & $1(0.5)$ & $4.066(0.022-2.748)$ & 0.255 \\
\hline \multicolumn{5}{|l|}{ Total cholesterol, mg/dL } \\
\hline$<200$ & 47 & 105 & 1.000 & \\
\hline $200-240$ & 27 & 63 & $0.957(0.543-1.688)$ & 0.881 \\
\hline$\geq 240$ & 19 & 18 & $2.358(1.136-4.897)$ & 0.021 \\
\hline \multicolumn{5}{|l|}{$\mathrm{TG}, \mathrm{mg} / \mathrm{dL}$} \\
\hline$<150$ & 63 & 139 & 1.000 & \\
\hline$\geq 150$ & 30 & 47 & $1.408(0.816-2.432)$ & 0.219 \\
\hline \multicolumn{5}{|l|}{ HDL cholesterol, mg/dL } \\
\hline$<40(\mathrm{M}),<50(\mathrm{~F})$ & 21 & 32 & 1.000 & \\
\hline$\geq 40(\mathrm{M}), \geq 50(\mathrm{~F})$ & 72 & 154 & $0.712(0.384-1.321)$ & 0.282 \\
\hline hs-CRP, mg/dL & $0.10 \pm 0.02$ & $0.11 \pm 0.02$ & & 0.752 \\
\hline AST, IU/L & $30.3 \pm 19.4$ & $29.5 \pm 16.4$ & & 0.013 \\
\hline ALT, IU/L & $29.4 \pm 21.0$ & $27.8 \pm 22.5$ & & 0.558 \\
\hline Alkaline phosphatase, IU/L & $63.9 \pm 17.5$ & $61.3 \pm 15.2$ & & 0.076 \\
\hline CEA, ng/mL & $2.0 \pm 1.1$ & $1.9 \pm 1.3$ & & 0.453 \\
\hline CA19-9, IU/mL & $8.0 \pm 7.3$ & $8.2 \pm 5.8$ & & 0.798 \\
\hline \multicolumn{5}{|l|}{ Visceral adipose tissue, $\mathrm{cm}^{2}$} \\
\hline Quartile I (M <33.9, F <23.0) & 14 & 55 & 1.000 & \\
\hline Quartile II (M 33.9-51.5, F 23.0-39.8) & 17 & 53 & $1.260(0.565-2.809)$ & 0.572 \\
\hline Quartile III (M 51.5-71.8, F 39.8-55.8) & 31 & 39 & $3.123(1.471-6.629)$ & 0.003 \\
\hline Quartile IV $(\mathrm{M}>71.98, \mathrm{~F}>55.80)$ & 31 & 39 & $3.123(1.471-6.629)$ & 0.003 \\
\hline \multicolumn{5}{|l|}{ Total adipose tissue, $\mathrm{cm}^{2}$} \\
\hline Quartile I (M <94.9, F <93.7) & 14 & 55 & 1.000 & \\
\hline Quartile II (M 94.9-119.6, F 93.7-119.9) & 17 & 53 & $1.260(0.565-2.809)$ & 0.572 \\
\hline Quartile III (M 119.6-146.1, F 119.9-148.8) & 27 & 43 & $2.467(1.155-5.269)$ & 0.020 \\
\hline Quartile IV (M >146.1, F >148.8) & 35 & 35 & $3.929(1.854-8.324)$ & $<0.001$ \\
\hline
\end{tabular}

Data are presented as number (\%) or mean \pm SD.

OR, odds ratio; CI, confidence interval; BMI, body mass index; HBsAg, hepatitis B surface antigen; HCV Ab, hepatitis C virus antibody; TG, triglyceride; HDL, high-density lipoprotein; hs-CRP, high-sensitivity C-reactive protein; AST, aspartate aminotransferase; ALT, alanine aminotransferase; CEA, carcinoembryonic antigen. 
186 age- and sex-matched subjects without GBP. Fifty-five of 965 males (5.7\%) and 38 of 650 females (5.9\%) had GBP (Fig. 2). The mean age was $48.3 \pm 10.4$ years and the incidence by age decades peaked in the fifth decade (Table 1 ).

The average size of GBP was $4.8 \pm 2.7 \mathrm{~mm}$ and the average number was $1.7 \pm 1.4$. Five subjects (5.4\%) with GBP of $\geq 10 \mathrm{~mm}$ underwent cholecystectomy and pathologic results revealed that four had cholesterol polyps and one adenomyomatosis (Table 2).

Comparisons of VAT and TAT between single versus multiple GBP were not significantly different $(\mathrm{p}=0.839$ and $\mathrm{p}=0.624$, respectively) (Table 3 ). In correlation analysis, GBP size was significantly associated with the TAT and VAT $(r=0.238, p=0.022$; $\mathrm{r}=0.210, \mathrm{p}=0.043$, respectively) (Figs 3 and 4).

\section{Analysis of risk factors}

By univariate analysis, hypertension, DM, HBsAg positivity, higher level of total cholesterol, the 3rd and 4th quartiles of VAT and TAT were significantly associated with GBP (Table 4). BMI and waist circumference were not meaningful variables. Finally, VAT (OR, 2.941, 95 \% CI, 1.325 to 6.529 with $\mathrm{p}=0.008$ for the highest quartile vs the lowest quartile and OR, 3.174, 95\% CI, 1.434 to 7.026 with $p=0.004$ for the 3 rd quartile vs the lowest quartile) and TAT (OR, 3.568, $95 \%$ CI, 1.625 to 7.833 with $\mathrm{p}=0.002$ for the highest quartile vs the lowest quartile and OR, 2.450, 95\% CI, 1.105 to 5.433 with $\mathrm{p}=0.027$ for the $3 \mathrm{rd}$ quartile vs the lowest quartile) were independent risk factors together with hypertension (OR, 2.512; 95\% CI, 1.381 to 4.569; $\mathrm{p}=0.003)$, DM (OR, 2.942; 95\% CI, 1.061 to 8.158; $\mathrm{p}=0.038$ ), and HBV positivity (OR, 3.548; 95\% CI, 1.295 to 9.716; $\mathrm{p}=0.014$ ) and higher level of total cholesterol (OR, 2.232, 95\% CI, 1.043 to $4.778, \mathrm{p}=0.039$ for $<200 \mathrm{mg} / \mathrm{dL}$ vs $\geq 240 \mathrm{mg} / \mathrm{dL}, \mathrm{p}=0.039$ ) by multivariate analysis (Table 5).

\section{DISCUSSION}

GBP are a common clinical finding, some of which possess malignant potential. Although the risk factors for GBP are not clearly established, the components of the metabolic syndrome such as dyslipidemia or glucose intolerance are reportedly important. ${ }^{7,8,11-13}$ However, there have been conflicting results about the relationship between GBP and obesity. In previous studies, obesity was evaluated by BMI, waist circumference, or waist-hip ratio. However, these anthropometric markers do not accurately reflect the volume of visceral fat that may play a

Table 5. Multivariate Analysis of Possible Risk Factors for Gallbladder Polyps

\begin{tabular}{|c|c|c|}
\hline Variable & OR $(95 \% \mathrm{CI})$ & p-value \\
\hline \multicolumn{3}{|l|}{ Hypertension } \\
\hline No & 1.000 & \\
\hline Yes & $2.512(1.381-4.569)$ & 0.003 \\
\hline \multicolumn{3}{|l|}{ Diabetes mellitus } \\
\hline No & 1.000 & \\
\hline Yes & $2.942(1.061-8.158)$ & 0.038 \\
\hline \multicolumn{3}{|l|}{ HBsAg } \\
\hline Negative & 1.000 & \\
\hline Positive & $3.548(1.295-9.716)$ & 0.014 \\
\hline \multicolumn{3}{|l|}{ Total cholesterol, mg/dL } \\
\hline$<200$ & 1.000 & \\
\hline $200-240$ & $0.813(0.449-1.471)$ & 0.494 \\
\hline$\geq 240$ & $2.232(1.043-4.778)$ & 0.039 \\
\hline \multicolumn{3}{|l|}{ Visceral adipose tissue, $\mathrm{cm}^{2}$} \\
\hline Quartile I (M <33.9, F <23.0) & 1.000 & \\
\hline Quartile II (M 33.9-51.5, F 23.0-39.8) & $1.098(0.563-3.077)$ & 0.527 \\
\hline Quartile III (M 51.5-71.8, F 39.8-55.8) & $3.174(1.434-7.026)$ & 0.004 \\
\hline Quartile IV (M > 71.98, F > 55.80) & $2.941(1.325-6.529)$ & 0.008 \\
\hline \multicolumn{3}{|l|}{ Total adipose tissue, $\mathrm{cm}^{2}$} \\
\hline Quartile I (M <94.9, F <93.7) & 1.000 & \\
\hline Quartile II (M 94.9-119.6, F 93.7-119.9) & $1.079(0.465-2.500)$ & 0.860 \\
\hline Quartile III (M 119.6-146.1, F 119.9-148.8) & $2.450(1.105-5.433)$ & 0.027 \\
\hline Quartile IV (M > 146.1, F > 148.8) & $3.568(1.625-7.833)$ & 0.002 \\
\hline
\end{tabular}

OR, odds ratio; CI, confidence interval; HBsAg, hepatitis B surface antigen. 
pivotal role in the pathogenesis of obesity-related diseases. To the best of our knowledge, this was the first study to evaluate the association between visceral obesity and GBP with the areas of adipose tissue measured by CT scan.

The pathogenesis of GBP is not fully understood. Lim et al. ${ }^{8}$ studied blood lipid profiles and concluded that obesity is a probable risk for GBP together with metabolic syndrome and insulin resistance. Segawa et al. ${ }^{7}$ investigated healthy Japanese to evaluate risk factors for GBP and showed that the prevalence rose with a rise in obesity index [modification of Broca's index; (body weight×100×0.9)/(height-100)]. They concluded that obesity contributes to the formation of cholesterol polyps of GB. However, obesity is not the only risk factor for GBP because the association is not consistent. Cantürk et al. ${ }^{13}$ conducted a study on 432 patients and found that patients with GBP had no severe obesity (BMI>30); however, they suggested that the formation of GBP is associated with fat metabolism. A Danish population study showed similar results. ${ }^{12}$ Also, a Chinese study with 243 patients found that BMI was not associated with GBP although glucose intolerance was a risk factor. ${ }^{11}$ These findings suggest that visceral fat tissue may be more important in the pathogenesis of GBP than obesity itself simply expressed by BMI. In the present study, we likewise found that BMI and waist circumference were insignificant variables. In addition, there were no differences in visceral obesity between multiple and single GBP. Furthermore, the correlations of TAT and VAT according to GBP size were not relatively low, although meaningful statistically.

Obesity is a strong risk factor for GB cancer. Of over 181,000 persons included in The Cancer Prevention Study II Nutrition Cohort, the relative risk of GB cancer was 1.8 (95\% CI, 1.1 to 2.9) in subjects with BMI of 30.0 to 34.9, as compared to those with normal BMI. Especially, obese women had a relative risk of 2.1 (95\% CI, 1.6 to 2.9), as compared to women with normal BMI. ${ }^{19}$ Larsson and Wolk ${ }^{20}$ concluded that obesity increases the risk of GB cancer in a meta-analysis of 3,288 cases. Visceral adipose tissue is not simply storage place for fat but a metabolicallyactive organ for both lipogenesis and lipolysis. During the processes, a number of cytokines involved in carcinogenesis of a variety of cancers including GB cancer such as insulin-like growth factor 1 (IGF-1), tumor necrosis factor $\alpha$, interleukin-6, and adiponectin are produced and secreted into portal circulation. ${ }^{21}$ For example, the IGF-1 receptor is an independent prognostic biomarker for GB cancer. ${ }^{22}$ Further investigations on the association of these cytokines and development of GB cancer or GBP are expected.

HBV positivity is a risk factor for GBP according to our data. This is not surprising, since many studies from endemic regions of HBV infection reported the same finding., ${ }^{3,23}$ Although not much is known on the role of HBV in GBP formation, Yang et al. ${ }^{24}$ suggested inflammatory reactions and alteration in bile composition as possible causes.

Despite its uniqueness, our study had several limitations. First, as this study was retrospective and of cross-sectional design, the duration of obesity was not estimated and temporal association between obesity and GBP could not be assessed. Secondly, the histology of polyps was confirmed only in a very small portion of subjects, which made subgroup analysis according to the histology not possible. It is admitted that GBP were not pathologic diagnosis but included variable disease entities. Finally, there may be a selection bias since the subjects were self-motivated for a health checkup and those who received both USG and CT might have higher socioeconomic status, both of which have not been reported as the risk factors for GBP.

In conclusion, visceral obesity measured by VAT and TAT was an independent risk factor for GBP together with hypertension, DM and HBV positivity and a higher level of total cholesterol. Prospective trials with sufficient numbers of patients and basic research that would explain underlying pathogenic mechanisms are expected in the future.

\section{CONFLICTS OF INTEREST}

No potential conflict of interest relevant to this article was reported.

\section{REFERENCES}

1. Lee KF, Wong J, Li JC, Lai PB. Polypoid lesions of the gallbladder. Am J Surg 2004;188:186-190.

2. Hayashi Y, Liu JH, Moriguchi H, et al. Prevalence of polypoid lesions of the gallbladder in urban and rural areas of Japan: comparison between 1988 and 1993. J Clin Gastroenterol 1996;23: 158-159.

3. Lin WR, Lin DY, Tai DI, et al. Prevalence of and risk factors for gallbladder polyps detected by ultrasonography among healthy Chinese: analysis of 34669 cases. J Gastroenterol Hepatol 2008; 23:965-969.

4. Pandey M, Khatri AK, Sood BP, Shukla RC, Shukla VK. Cholecystosonographic evaluation of the prevalence of gallbladder diseases: a university hospital experience. Clin Imaging 1996;20:269272

5. Yang HL, Sun YG, Wang Z. Polypoid lesions of the gallbladder: diagnosis and indications for surgery. Br J Surg 1992;79:227-229.

6. Wan YL. Polypoid lesions of the gallbladder. Zhonghua Wai Ke Za Zhi 1989;27:450-453.

7. Segawa K, Arisawa T, Niwa Y, et al. Prevalence of gallbladder polyps among apparently healthy Japanese: ultrasonographic study. Am J Gastroenterol 1992;87:630-633.

8. Lim SH, Kim DH, Park MJ, et al. Is metabolic syndrome one of the risk factors for gallbladder polyps found by ultrasonography during health screening? Gut Liver 2007;1:138-144.

9. Kim SY, Lee HS, Lee YS, et al. Prevalence and risk factors of gallbladder polyp in adults living in Daegu and Gyeongbuk provinces. Korean J Gastroenterol 2006;48:344-350. 
10. Shim SG, Lee KT, Lee JK, et al. Prevalence and risk factors of gallbladder polyps in health screening subjects. Korean J Med 1999;57:1014-1020.

11. Chen CY, Lu CL, Chang FY, Lee SD. Risk factors for gallbladder polyps in the Chinese population. Am J Gastroenterol 1997;92:2066-2068.

12. Jorgensen T, Jensen KH. Polyps in the gallbladder: a prevalence study. Scand J Gastroenterol 1990;25:281-286.

13. Cantürk Z, Sentürk 0, Cantürk NZ, Anik YA. Prevalence and risk factors for gall bladder polyps. East Afr Med J 2007;84:336-341.

14. Tokunaga K, Matsuzawa Y, Ishikawa K, Tarui S. A novel technique for the determination of body fat by computed tomography. Int J Obes 1983;7:437-445.

15. Goodpaster BH. Measuring body fat distribution and content in humans. Curr Opin Clin Nutr Metab Care 2002;5:481-487.

16. Park YS, Kwon HT, Hwang SS, et al. Impact of visceral adiposity measured by abdominal computed tomography on pulmonary function. J Korean Med Sci 2011;26:771-777.

17. World Health Organization, Regional Office for the Western Pacific; International Diabetes Institute; International Association for the Study of Obesity; International Obesity Task Force. The AsiaPacific perspective: redefining obesity and its treatment. Sydney: Health Communications Australia, 2000:19-20.

18. National Cholesterol Education Program (NCEP) Expert Panel on Detection, Evaluation, and Treatment of High Blood Cholesterol in Adults (Adult Treatment Panel III). Third Report of the National Cholesterol Education Program (NCEP) Expert Panel on Detection, Evaluation, and Treatment of High Blood Cholesterol in Adults (Adult Treatment Panel III) final report. Circulation 2002;106:3143-3421.

19. Calle EE, Rodriguez C, Jacobs EJ, et al. The American Cancer Society Cancer Prevention Study II Nutrition Cohort: rationale, study design, and baseline characteristics. Cancer 2002;94:500-511.

20. Larsson SC, Wolk A. Obesity and the risk of gallbladder cancer: a meta-analysis. Br J Cancer 2007;96:1457-1461.

21. John BJ, Irukulla S, Abulafi AM, Kumar D, Mendall MA. Systematic review: adipose tissue, obesity and gastrointestinal diseases. Aliment Pharmacol Ther 2006;23:1511-1523.

22. Kornprat P, Rehak P, Rüschoff J, Langner C. Expression of IGF-I, IGF-II, and IGF-IR in gallbladder carcinoma: a systematic analysis including primary and corresponding metastatic tumours. J Clin Pathol 2006;59:202-206.

23. Lai SW, Lai HC, Liu CS, Liao KF, Lin T, Lin CC. The prevalence of gallbladder polyps is higher in HBsAg positive population. Acta Gastroenterol Belg 2010;73:294-295.

24. Yang HL, Kong L, Hou LL, et al. Analysis of risk factors for polypoid lesions of gallbladder among health examinees. World J Gastroenterol 2012;18:3015-3019. 